\title{
Older people's use of ambulance services: a population based analysis
}

\author{
Michele J Clark, Gerry FitzGerald
}

\begin{abstract}
Objective-To investigate the use of emergency and non-urgent ambulance transport services by people aged 65 years and over.

Setting-The study was undertaken in Queensland where the Queensland Ambulance Service (QAS) is the sole provider of emergency pre-hospital and non-urgent ambulance services for the entire state.

Methods-The age and sex of 351000 emergency and non-urgent cases treated and transported by the QAS from July 1995 to June 1996 were analysed.

Results-People aged 65 years and over who comprise $12 \%$ of the population utilise approximately one third of the emergency and two thirds of the nonurgent ambulance resources provided in Queensland. While the absolute number of occasions of service for females for emergency services is higher than for males, when the data are stratified for age and sex, males have higher rates of emergency ambulance service utilisation than females across every age group, and particularly in older age groups. Gender differences are also found for non-urgent ambulance usage. The absolute number of occasions of service for older females aged 65 and over using non-urgent ambulance transport is high, but utilisation patterns on stratified data reveal similar gender usage patterns across most age groupings, except at the older age groupings where male usage greatly exceeds female usage. Conclusions-As the aged are disproportionately high users of ambulance services, it will become increasingly important for ambulance services to plan for the projected increase in the aged population. Emergency pre-hospital care is one of the few health services along the continuum of care where male usage patterns are higher than those of females. More information needs to be obtained on the age and presenting characteristics of those people who are multiple users of the ambulance service. Such information will assist service planners.

(F Accid Emerg Med 1999;16:108-111)
\end{abstract}

Keywords: pre-hospital care; ambulance services; emergency transport; older people

Ambulance services play an important part in the continuum of health care. Historically, ambulance services in Australia and other parts of the world have not been a focus of research attention and this is particularly the case in relation to geriatric populations. While older people's use of acute hospital beds, emergency departments, ${ }^{23}$ general practitioner and diagnostic services ${ }^{4}$ has been well documented, pre-hospital care or ambulance usage has remained a relatively neglected area of research. This is surprising given the key part that ambulance services play in providing prehospital care and transport in emergency and non-emergency situations.

The Queensland Ambulance Service (QAS) is a statewide public sector administered service, providing coverage to the entire Queensland population of 3.3 million people. It has 206 locations throughout the state, employs 1900 permanent staff, and utilises the skills of 350 voluntary ambulance officers. An act of parliament precludes other providers from providing emergency transportation, giving QAS a monopoly status. Currently there are no private for-profit providers of routine ambulance transports. Because QAS is the sole provider of the comprehensive range of ambulance transport services on a statewide basis, it holds a comprehensive and relatively unique dataset on all occasions of service including patient demographic information.

All requests for ambulance assistance are triaged by QAS communication centres using a medical priority dispatching system according to three categories or codes of clinical severity. Codes 1 and 2 are considered life threatening or urgent, respectively, and both require a rapid response. A code 3 is considered to be non-urgent or of a routine nature and does not require an immediate response. Code 3 cases include requests for assistance with transportation to hospital medical appointments and transportation from one health facility to another.

To date, little analysis has been undertaken in Australia of the patterns of population utilisation of ambulance services in general or of utilisation patterns of older people aged 65 years and over in particular. As the proportion of older people in the population is expected to rise from $11.8 \%$ to $20.3 \%$ by the year $2031^{5}$ health services will need to examine strategically the current and projected utilisation patterns. This study presents the utilisation patterns of ambulance services in Queensland over a one year period with particular focus on older people's use of ambulance services for emergency and non-urgent cases.

\section{Methods}

A case sheet is completed for all requests to which the QAS responds and core data from case sheets are then read into the computerised 
Table 1 Age/sex usage by transport type per 1000 population 1995-96

\begin{tabular}{|c|c|c|c|c|c|c|}
\hline \multirow[b]{2}{*}{ Age } & \multicolumn{3}{|c|}{ Emergency/urgent services $\left(n=190458^{*}\right)$} & \multicolumn{3}{|c|}{ Non-urgent services $(n=160547 t)$} \\
\hline & $\begin{array}{l}\text { Male } \\
\text { usage } \\
\text { (\%) }\end{array}$ & $\begin{array}{l}\text { Total males and } \\
\text { females }\end{array}$ & $\begin{array}{l}\text { Use per } \\
1000\end{array}$ & $\begin{array}{l}\text { Male } \\
\text { usage } \\
(\%)\end{array}$ & $\begin{array}{l}\text { Total males and } \\
\text { females }\end{array}$ & $\begin{array}{l}\text { Use per } \\
1000\end{array}$ \\
\hline $0-4$ & 56.9 & 8331 & 37.6 & 55.1 & 2312 & 10.4 \\
\hline $5-9$ & 61.1 & 4917 & 21.7 & 58.3 & 662 & 2.9 \\
\hline $10-14$ & 62.6 & 8766 & 38.8 & 57.9 & 958 & 4.2 \\
\hline $15-19$ & 54.4 & 12583 & 52.6 & 54.8 & 1784 & 7.5 \\
\hline $20-24$ & 55.6 & 12880 & 54.9 & 48.2 & 2406 & 10.3 \\
\hline $25-29$ & 55.2 & 11351 & 49.7 & 45.8 & 2646 & 11.6 \\
\hline $30-34$ & 53.5 & 10825 & 45.9 & 46.1 & 2946 & 12.5 \\
\hline $35-39$ & 56.2 & 9896 & 44.6 & 46.5 & 4089 & 18.4 \\
\hline $40-44$ & 59.0 & 8974 & 40.6 & 45.5 & 3981 & 18.0 \\
\hline $45-49$ & 59.4 & 8994 & 50.2 & 49.7 & 5816 & 32.5 \\
\hline $50-54$ & 58.5 & 8409 & 58.2 & 50.5 & 7087 & 49.0 \\
\hline $55-59$ & 57.0 & 8057 & 65.5 & 51.3 & 8048 & 65.5 \\
\hline $60-64$ & 57.8 & 8705 & 67.8 & 51.6 & 11331 & 88.2 \\
\hline $65-69$ & 57.7 & 11947 & 99.4 & 54.8 & 17244 & 143.4 \\
\hline $70-74$ & 54.0 & 14892 & 158.3 & 45.8 & 20392 & 216.7 \\
\hline $75-79$ & 49.3 & 14855 & 222.0 & 46.0 & 23676 & 353.8 \\
\hline $80-84$ & 42.6 & 13754 & 355.3 & 40.8 & 22215 & 573.9 \\
\hline $85-89$ & 36.5 & 8339 & 473.8 & 35.6 & 14960 & 850.0 \\
\hline $90+$ & 30.0 & 3983 & 523.3 & 28.8 & 7994 & 1050.0 \\
\hline
\end{tabular}

^ 1448 male and 1125 female emergency/urgent cases missing age information.

$\nmid 1302$ male and 1690 female non-urgent cases missing age information.

Ambulance Information Management System (AIMS). Additionally, a microfiche copy of each case record is held by the QAS. AIMS was introduced on 1 July 1995 and provides data on a whole of state basis.

The age and sex of patients using emergency (codes 1 and 2) and non-urgent ambulance services (code 3 ) for the year 1 July 1995 to 30 June 1996 was extracted from the AIMS database for all requests involving ambulance treatment or transport. Data were organised in five year age groupings. The population figures from the 1991 Australian Bureau of Statistics census were used to calculate usage patterns for gender and age groupings.

\section{Results}

After excluding 5565 cases from the analysis due to missing or incomplete age details, usable data were available on 351005 cases.

\section{EMERGENCY AMBULANCE USAGE}

Use of emergency ambulance services increased with age with the exception of the first four years of life (table 1). There was a 30\% increase in usage in the 65-69 year age group compared with the 60-64 age group and the utilisation rates continued to increase rapidly in the following five age groups (table 2). People 65 years of age and older utilise over one third $(35.6 \%)$ of all ambulance emergency resources. Over half of the demand for emergency ambulance services from birth through until the age of 74 years can be attributed to males $(56.8 \%)$. When the data were stratified for age and sex, males made higher use of emergency ambulance services than females across all age groups and particularly in later years as shown in table 2 .

NON-URGENT AMBULANCE USAGE

Table 1 provides information on the usage patterns for non-urgent ambulance assistance and transport. Once again it can be seen that except for the first four years of life, demand for nonurgent ambulance services increased with age.
Table 2 Occasions of service rates for males and females per 1000 population: emergency transport

\begin{tabular}{lll}
\hline Age & Male utilisation & Female utilisation \\
\hline $0-4$ & 41.6 & 33.4 \\
$5-19$ & 43.3 & 32.4 \\
$20-59$ & 56.5 & 43.5 \\
$60-64$ & 79.2 & 56.6 \\
$65-69$ & 117.7 & 82.0 \\
$70-74$ & 185.0 & 135.3 \\
$75-79$ & 255.4 & 197.0 \\
$80-84$ & 389.9 & 333.4 \\
$85-89$ & 507.1 & 456.6 \\
$90+$ & 647.0 & 483.6 \\
\hline
\end{tabular}

Table 3 Occasions of service rates for males and females per 1000 population: non-urgent transport

\begin{tabular}{lll}
\hline Age & Male utilisation & Female utilisation \\
\hline $0-4$ & 11.2 & 9.7 \\
$5-19$ & 5.4 & 4.4 \\
$20-59$ & 22.7 & 23.9 \\
$60-64$ & 92.1 & 84.5 \\
$65-69$ & 161.2 & 126.6 \\
$70-74$ & 215.1 & 218.1 \\
$75-79$ & 380.4 & 333.9 \\
$80-84$ & 603.2 & 555.2 \\
$85-89$ & 867.0 & 830.9 \\
$90+$ & 1248.0 & 986.8 \\
\hline
\end{tabular}

As with emergency usage, demand grew steadily until 60-64 years of age after which it increased rapidly. There was a $55 \%$ increase from the 60-64 age group compared to the 65-69 age group. Those aged 65 years and over account for approximately two thirds (64.5\%) of non-urgent ambulance demand. Older people aged 65 years and over made considerably higher demand on non-urgent ambulance assistance than emergency pre-hospital care and transport (table 1). There were differences in the crude occasions of male and female usage with males in the younger (birth to 19 years) and older age groups (70 years and older) making more and less use of non-urgent ambulance services respectively (table 1). However, when the data for non-urgent ambulance usage were stratified for age and sex, the demand patterns of males and females were fairly similar across most age groupings until the age of 75 years and older when the demand for services for males greatly exceeded that of females. The exception was the 65-69 age group, where males made considerably higher use of non-urgent ambulance services than females (table 3).

\section{Discussion}

Older people place high levels of demand on both emergency and non-urgent ambulance services. People aged 65 years and older comprise approximately $12 \%$ of the population, ${ }^{5}$ but consume one third of emergency ambulance services and two thirds of non-emergency services.

EMERGENCY AMBULANCE USAGE

The use of ambulance services for medical emergencies is largely driven by clinical need, ${ }^{67}$ including the time urgency of the condition. ${ }^{8}$ Providing high quality pre-hospital care to prevent loss of life and severity of illness in the pre-hospital context is a core goal of the QAS. ${ }^{9}$ Apart from working collaboratively with 
other agencies in relation to health promotion and injury prevention strategies, there is little that an ambulance service could do, or would wish to do, to reduce the level of demand for emergency ambulance care and transport.

There are notable differences in the usage patterns of males and females, including into older age and these differences may be explained by epidemiological and demographic factors. Males and females have different patterns of mortality and morbidity with male life expectancy being approximately six years less than female life expectancy ${ }^{5}$ and with males being more likely to suffer from complaints requiring emergency care, including heart disease, accidents, and injury. ${ }^{10}$ Hospital emergency departments are a major destination point for ambulances. Males are more likely to use emergency departments than females, ${ }^{11}{ }^{12}$ which may explain in part the high use of ambulance emergency services by males. Paradoxically, females make higher use of hospital beds, ${ }^{13}$ but males are high users of emergency services, such as hospital accident and emergency departments and in this study, were high users of emergency pre-hospital care. While epidemiological and demographic differences may account for some of the differences in gender usage patterns, it is likely that medicosocial and pragmatic factors may account for some of the gender differences in demand for emergency ambulance services. It is thought for example, that males may delay medical intervention and conditions may then be urgent by the time assistance is sought. Pragmatic factors such as weight differences between males and females may mean that it is more feasible for informal carers such as family, neighbours, and friends to assist with transportation needs of females, even in emergency situations.

Men's health is an emerging area of research and policy attention so that gender differences in relation to ambulance usage require further investigation. Emergency pre-hospital care is one aspect of the continuum of care where males are placing more demand on services than females and the reasons for this, including gender difference in the experience of what constitutes a medical emergency, requires investigation. Wofford et al found no association between gender and emergency prehospital usage ${ }^{14}$; however their study was undertaken in a health care system markedly different from Australia and was based on data collected from one county in the United States of America.

NON-URGENT AMBULANCE USAGE

It is in relation to non-urgent ambulance usage that factors other than clinical need clearly come to the fore in influencing demand for services. Demographic and epidemiological factors, social and historical factors, economic incentives, and hospital practices are all likely to impact on demand for non-urgent ambulance services. With the aging of the population, there is an increase in the number of people likely to develop age related disability, ${ }^{15}$ and these disabilities can extend over a consider- able number of years. Many of the disabilities of aging affect mobility and independence, thus affecting older people's ability to use cars, taxis, and public transport. While only a small proportion of community based older people require help with personal care, a far greater number experience difficulty with or require assistance with transport, ${ }^{16}$ and the current study is in keeping with this finding. Carers too may be old and be unable to assist with the physical demands of helping the patient to access medical and treatment appointments. Single people have been found to place more demand on non-urgent ambulance services than married, defacto or separated patients, ${ }^{68}$ also suggesting that sociological factors impact on non-urgent ambulance usage. Aged people are more likely to live alone than people from other segments of the population, possibly placing them at greater risk of requiring transport assistance from ambulance services. As the number of households with single occupancy increases, it is likely that changing household compositions will impact on demand for routine ambulance. Cohort factors are known to influence demand for health and social services. ${ }^{5}$ Many older women belong to an age cohort that did not drive a motor vehicle, making them reliant on family, friends, neighbours, and potentially ambulance services for assistance with transport to medical appointments. Historical factors may also influence older people's demand for nonurgent ambulance services. The QAS has undergone considerable cultural and administrative reform in the area of routine ambulance transport in order to better target scarce ambulance resources to assessed need. However, health professionals including ambulance officers, report that many subscribers (see endnote) view usage as an entitlement even if that level of assistance is not medically required. Additionally, medical practitioners are gate keepers to the routine or non-urgent transport system, and some may be loath to deny their patients access to an ambulance for non-urgent transportation even if they think it medically unnecessary. The QAS has sought in recent years to tighten the guidelines for non-urgent usage by requiring a doctor's authorisation that ambulance assistance is medically necessary. Routine transport caseloads have reduced by fewer than half in the five year period from 1991-92 while emergency cases have increased by $15 \%$ for the same time period. ${ }^{17}$ This change in utilisation suggests a greater degree of elasticity in non-urgent treatment and transportation than with emergency pre-hospital care. It is likely that substitutes can be found for non-urgent transportation such as private vehicles or taxis and that this degree of substitution does not extend to demand for emergency pre-hospital assistance.

Finally, field workers and senior ambulance managers report that recent hospital practices are impacting on ambulance services. ${ }^{18}$ Moves toward shorter hospital lengths of stay, early discharge practices, day surgery, and contracting out of imaging and related services are four trends that have been attributed with 
increasing demand for ambulance services and these changes may have a disproportionate impact on older people. Shorter lengths of stay and early discharge may mean that older people have difficulty travelling home in a private car due to limited range of movement and other medical reasons. Alternatively, patients may return to hospital as an outpatient for ongoing treatment that once would have been provided as part of the inpatient episode of care, and, although it is not possible to quantify, some of this transport is being provided by ambulance services. Increased use of day surgery may mean that people require ambulance assistance to and particularly from these treatments. Recently, an increasing number of Queensland public hospitals have contracted out a range of imaging services, which may result in increased demand for interhospital or interfacility transfers. It is likely that the changes to hospital practices have individually and cumulatively increased demand for nonurgent ambulance services.

\section{Conclusion}

While this study was able to provide information on usage patterns across the entire state of Queensland, the AIMS dataset does not provide information on multiple users of services, as each case is given a unique identification number. It is not known to what extent the demand patterns for emergency and nonurgent treatment and transport are being affected by multiple users. As the occasions of service for non-urgent transport for males at the oldest age grouping exceeds 1000 for every 1000 males alive in the population in that age group, it is evident that some individuals are using the service more than once in any given year. Ambulance officers report anecdotally that some patients with particular medical conditions, such as those requiring renal dialysis, are long term, repeat users of ambulance service. Further information is needed on repeat users. In some locations in Queensland, ambulance officers have been included in case management meetings with other health professionals, in order to assist in the coordination of services between formal and informal health and social care providers for older people with complex care needs.

If demand across the age groups remains constant, population aging will have a significant impact on both emergency and nonurgent ambulance services. As more people join the ranks of the aged, and as average life expectancy increases, ambulance services across Australia will need to address the result- ant resource implications. Ambulance services are one of the few health services where male usage exceeds that of females. As the issue of men's health, and particularly older men's health gains research and policy attention, it will be important to understand the medical and sociomedical determinants of male demand on ambulance services.

This research was undertaken with the assistance of a postdocThis research was undertaken with the assistance of a postdoc-
toral fellowship from the Public Health Research and Development Committee of the National Health and Medical Research ment Committee of the National
Council (grant number 964226).

Endnote: For a relatively small sum of money, individuals can insure against the likelihood of needing to use an ambulance through a subscription or insurance scheme that is operated by
the QAS. Approximately $60 \%$ of the Queensland population is the QAS. Approximately $60 \%$ of the Queensland population is QAS for emergency and non-emergency treatment and QAS for emergency and non-emergency treatment and
transport at no additional out-of-pocket expense. Nonsubscribers can also use the QAS on a fee for service basis, which includes a fixed call out fee and a variable component based on mileage.

1 Australian Institute of Health and Welfare. Australia's health 1996: the fifth biennial report of the Australian Institute of Health and Welfare. Canberra: Australian Government Printing Service, 1996.

2 Lamb I, Eddey D, Cameron P. Emergency department utilisation by the elderly. Emerg Med 1995;7:75-9.

3 Street P, McKay S, Allpleby N, et al. Emergency department use by the elderly: a study of older people's use of the emergency departments of three Melbourne hospitals. Melbourne: Bundoora Centre for Applied Gerontology, 1996.

4 Haas M, Rushworth RL, Rob MI. Health services and the elderly: an evaluation of utilisation data. Australian fournal of Ageing 1995,13:176-80.

5 Borowski A, Hugo G. Demographic trends and policy Borowski A, Hugo G. Demographic trends and policy
implications. In: Borowski A, Encel S, Ozanne E, eds. Ageimplications. In: Borowski A, Encel S, Ozanne E, eds. Ageing and social policy in Australia.
University Press, 1997:19-53.

6 Butler JRG. Factors affecting the demand for ambulance services. Int $\mathcal{f}$ Trans Econ 1981;8:225-38.

7 Butler JRG. Estimating the welfare loss from non-optimal pricing of ambulance services. Int $\mathcal{F}$ Trans Econ 1983;20:77110.

8 Clark MJ, Purdie J, Bischoff NG, et al. Emergency prehospital ambulance services: an evaluation of unmet need. No 1 of the Australian Centre for Prehospital Research Monograph Series. Brisbane: GoPrint, 1998.

9 Department of Emergency Services. Annual report 1993/94. Brisbane: GoPrint, 1994.

10 Broom D. Masculine medicine, feminine illness: Gender and health. In: Lupton GM, Naiman JM, eds. Sociology of health and illness. 2nd Ed. Melbourne: Macmillan, 1995: 121-34.

11 FitzGerald GJ. Emergency department triage. (Dissertation.) Brisbane: University of Queensland, August 1989.

12 Walker LL. Inpatient and emergency department utilization: the effects of distance, social class, age, sex and marital status. Fournal of the American College Emergency Physicians 1976;5:105-10.

13 Abraham B, d'Espaignet ET, Stevenson C. Australian health trends 1995. Canberra: Australian Institute of Health and Welfare, 1995.

14 Wofford JL, Moran WP, Heuser MD, et al. Emergency medical transport of the elderly: a population-based study. Am f Emerg Med 1995,13:297-300.

15 McCallum J. Health and ageing: the last phase of the epidemiological transition. In: Borowski A, Encel S, Ozanne E, miological transition. In: Borowski A, Encel S, Ozanne E, eds. Ageing and social policy in Australia.
bridge University Press, 1995: 54-73.

16 Australian Bureau of Statistics. Disability, ageing and carers. Canberra: Australian Bureau of Statistics, 1993.

17 Department of Emergency Services and Office of Sport and Recreation. Annual report 1995/96. Brisbane: GoPrint, 1996.

18 Clark MJ. Workforce planning field visits: summary of findings. A research report to the Queensland Ambulance Service. Brisbane: University of Queensland, 1996. 